Pediat. Res. 2: 388 (1968)

\title{
Presentation of Howland Award to Paul György
}

\author{
L.A.BARNESS \\ Department of Pediatrics, Hospital of the University of Pennsylvania, \\ Philadelphia, Pennsylvania, USA
}

It is unusual to present the Howland Award to a member of the American Pediatric Society who is also eligible for active membership in the Society for Pediatric Research. It is only fitting, however, to present this award to a man whose career has been related to Dr. Howland's career in many ways and yet who has proved that Ponce de Leon was right.

The man we honor today was born in Hungary, went to medical school in Hungary and Germany, and for his first career, at the time of multiple deficiency diseases in children, made notable contributions to the study and prevention of rickets in children.

He then began a second career covering Germany, England, and the United States during which time he discovered vitamins $\mathrm{B}_{6}$, riboflavin, and biotin. In these researches, as in all his activities, he was assisted, encouraged, and organized by his wife whose understanding and ability, as well as her sympathy for children and excellence as a cook, made his work meaningful.

His third career at Western Reserve and the University of Pennsylvania was characterized by his ability as a teacher, investigator, pediatrician, and stimulator. $\mathrm{He}$ is one of that rare breed of old-time pediatricians who is a total pediatrician; yet he recognized the development of pediatric specialists and was quick to help develop them. In Philadelphia, he developed a nutrition laboratory from which has originated many of our present feeding practices of infants. Yet in all his research, as in his teaching and practice, his first consideration was that no harm be done to children. About this period one of his former students has written, and everyone who was taught by him can only concur, ' $\mathrm{He}$ was a remarkably informed medical scholar, perceptive and valid clinician. But what a gloriously bombastic, colorful, emphatic ward-rounder and teacher. In a circumstance in which his associates, like many contemporary pediatric professors, had retreated into preoccupation with narrowly topical themes, he eagerly dealt with all of pediatrics. He exerted himself, in characteristic social violence, to accomplish the pediatric education of his proteges. We are fortunate. Please mention, also, that his proteges were important enough to him that he remembered them for 20 years, as in my instance.'

During this period he also concerned himself with trying to learn why nature had developed human milk to be so different from other milks. From these studies, he isolated several nonspecific resistance factors and he continues working on this. However, he is best noted by his students during this period for his unique observation, 'Cows milk is for the calf'.

When he reached the usual retirement age, he began yet a fourth career. He became active in the WHO and in the sociology, biochemistry, and nutrition of technically developing countries, particularly relating to the welfare of children. His contributions in this area are now beginning to be felt in this country and abroad.

He has not been unhonored. He has received many important awards in pediatrics and nutrition. He has been blessed by three superb sons, a particularly complementary wife, and an unexhaustible energy.

Our Society is honored to present the Howland Award to the very young Dr. Paul György. 